\title{
El Criminal Compliance: la Responsabilidad Penal de las personas jurídicas y el cumplimiento normativo
}

Giovanna Abad Saldaña

Abogada por la Universidad de Lima. Máster en Gobernabilidad y Gestión Pública. Profesora visitante de la Universidad Nacional de Lomas de Zamora en Argentina.

SUMARIO:

I. Introducción.

1. ¿El fin del "societas delinquere non potest"?

2. La definición del Compliance.

3. El rol de la empresa en la economía del mundo moderno.

II. El nuevo marco de Responsabilidad Penal de las personas jurídicas.

1. El delito corporativo y el Compliance.

2. La responsabilidad administrativa de las personas jurídicas y el criminal Compliance.

III. El derecho penal y las personas jurídicas: el caso peruano.

1. El artículo 105 del Código Penal peruano.

2. La Ley 30424 y el Decreto Legislativo 1352.

3. ¿Responsabilidad Penal o Administrativa?

4. La doble dimensión del Compliance.

IV. Conclusiones.

* El artículo fue recibido con fecha 20-05-19. 


\section{RESUMEN:}

Como parte de la expansión del derecho penal y la regulación de los delitos de peligro abstracto para la protección del bien jurídico "seguridad común", nos encontramos frente a un nuevo escenario del derecho penal en el campo jurídico-empresarial, que plantea un cambio en la visión que hasta hace una década atrás se tenía sobre la responsabilidad penal de las personas jurídicas y las sanciones a los delitos cometidos en el marco de actividades societarias. En este nuevo contexto, es importante analizar las dos grandes posiciones doctrinarias del derecho penal empresarial, haciendo un importante comparativo entre el axioma jurídico "societas deliquere non potest" —la sociedad no puede delinquir - frente a la moderna posición de la responsabilidad penal de las personas jurídicas derivada de las actividades criminales de sus socios, accionistas o representantes que se cometan bajo el velo empresarial y usando la estructura social. Surge entonces, la figura del cumplimiento normativo en el ámbito del derecho penal, o criminal Compliance como se conoce en el derecho anglosajón; esta, relativamente nueva, herramienta jurídica para el derecho occidental y para el derecho penal peruano, establece un nuevo orden legal que regula la correcta actuación empresarial, distinguiendo la responsabilidad de la persona jurídica frente a las conductas delictivas de sus socios o representantes. Este mecanismo del cumplimiento normativo será desarrollado en el presente artículo, analizándose su contexto, importancia, implicancias y su proyección hacia las próximas décadas.

Palabras clave: Compliance, cumplimiento normativo, personas jurídicas, derecho penal económico, criminal Compliance.

\section{ABSTRACT:}

As a part of the expansion of criminal law and the regulation of crimes of abstract danger for the protection of the legal right "common security", we are facing a new scenario of criminal law in the legal-business field, which proposes a change in the vision that until a decade ago was held about the criminal responsibility of legal persons and the sanctions for crimes committed in the framework of corporate activities. In this new context, it is important to analyze the two doctrinal positions of corporate criminal law, making an important comparison between the legal axiom "societas deliquere non potest" -society can not commit a crime- versus the modern position of criminal responsibility legal persons derived from the criminal activities of their partners, shareholders or representatives that are committed under the corporate veil and using the social structure. Then, there is the figure of regulatory Compliance in the field of criminal law, or criminal Compliance as it is known in Anglo-Saxon law; This, relatively new, legal tool for Western law and for Peruvian criminal law, establishes a new legal order that regulates the correct business performance, distinguishing the liability of the legal entity against the criminal behavior of its partners or representatives. This mechanism of regulatory compliance will be developed in this article, analyzing its context, importance, implications and its projection to the next decades.

Keywords: Compliance, regulatory Compliance, legal persons, economic criminal law, criminal Compliance.

\section{INTRODUCCIÓN}

\section{1. ¿El fin del "societas delinquere non potest"?}

La respuesta a esta pregunta es aún tema de análisis y debate en varios aspectos. La doctrina no es unánime en este tema y, frente a la posición del derecho penal moderno que nos orienta hacia el nuevo modelo de responsabilidad penal de las personas jurídicas, subsiste la doctrina que no reconoce abiertamente la existencia de una responsabilidad penal de las personas jurídicas; el caso peruano es un claro ejemplo de este segundo esquema doctrinario conforme se desprende de la normativa aprobada por la Ley 30424 y sus modificacio- nes, que regula lo que se ha denominado "responsabilidad administrativa -autónoma-" de las personas jurídicas dentro de un proceso penal, incorporándose la herramienta del "Compliance" como el instrumento de gestión necesario para establecer el marco del cumplimiento normativo que se exige a la empresa, manteniendo vigente la regulación de las "consecuencias accesorias para las personas jurídicas" contempladas en el artículo 105 del Código Penal peruano.

El principio "societas deliquere non potest" traducido como la imposibilidad de que la persona jurídica pueda cometer delitos, pertenece al derecho penal clásico. Su sustento radica en la teoría de la ficción jurídica que crea a los 
entes empresariales. A decir del Dr. Carlos Gómez-Jara:

"En la discusión jurídico-penal en torno a la responsabilidad penal de las personas jurídicas aparece, en unas más veladas que en otras, la crítica de que, en última instancia, las únicas personas que existen en el mundo real son las personas físicas y no las personas jurídicas"

En concordancia con esta doctrina del derecho penal clásico, las personas jurídicas, por su naturaleza incorpórea y por ser producto de una ficción del derecho, se sostiene que no pueden desarrollar conductas típicas ni asumir culpabilidad directa; entonces, al no resultar aplicable la teoría del delito a una persona jurídica, no es posible imponerle una sanción penal, pudiendo únicamente sufrir las consecuencias accesorias derivadas de la pena impuesta a las personas físicas que, actuando en nombre y/o representación de la empresa, sean condenadas por la comisión de un delito.

\section{La definición de Compliance.}

Es importante entonces establecer una definición clara y práctica de lo que se entiende por Compliance en el campo del derecho penal. En España, donde la doctrina del Compliance está muy desarrollada, éste se define como:

"el conjunto de herramientas de carácter preventivo con el objeto de prevenir la infracción de normas de carácter penal y evitar eventuales sanciones que generen responsabilidad a la empresa"2.

En general, el Compliance se define como un mecanismo que establece estándares normativos de cumplimiento para garantizar la fidelidad de la empresa a las normas éticas y legales.

\section{El rol de la empresa en la economía del mundo moderno.}

El derecho es una ciencia que evoluciona juntamente con los avances en el comportamiento humano. Su esencia es el control como mecanismo para preservar la tranquilidad y la convivencia armónica de una sociedad.

En el mundo moderno y globalizado, la empresa se ha posicionado más allá de su espacio de negocio. La empresa es hoy un eje esencial en la economía y sus actividades industriales, de producción de bienes y servicios tienen una influencia importante en el crecimiento de los mercados económicos.

En este contexto, el Estado, como ente jurídico, es también un actor social de gran trascendencia, en la medida que se vincula directa e indirectamente con el sector privado a través de las compras estatales y los contratos de obras y de servicios. Es así que Estado y empresa se convierten en un binomio importante, surgiendo la necesidad de regular las contrataciones con el Estado, la libre competencia, las reestructuraciones empresariales y en general, la existencia de reglas claras en el derecho administrativo y en la administración pública. El derecho penal no es ajeno a esta realidad, por cuanto el dinamismo de los cambios sociales, producen nuevas conductas que lesionan bienes jurídicos socialmente protegidos. Es así que, como producto de esta estrecha relación entre Estado y empresa, es sumamente importante proteger jurídicamente los elementos esenciales de la actividad empresarial, como son la confianza, la buena fe en los negocios, la competencia, la promoción del acceso a los mercados en igualdad de oportunidades, todo ello en un marco de legalidad y transparencia.

Sin embargo, en las últimas décadas, la corrupción surge como un factor negativo, cada vez

1. GÓMEZ-JARA DIEZ, Carlos. Compliance y Responsabilidad Penal de las Personas Jurídicas en el Perú. Primera Edición. Lima: Instituto Pacífico, Febrero 2018.

2. CUEVAS, José Alejandro. Compliance y Defensa Penal. Madrid: Garberi Penal - Compliance y Defensa Penal, 2017. 
más visible, que afecta el adecuado desarrollo de todos estos principios básicos. La preocupación por desterrar la corrupción es importante porque ésta afecta directamente el adecuado y normal desarrollo de la relación Estado-empresa; incide negativamente en la economía, en tanto la corrupción, afecta la libre competencia y la igualdad de oportunidades mediante el favorecimiento indebido a los actores involucrados, entre otros factores. La corrupción lesiona un bien jurídico primordial que es el deber del servidor público que ostenta el dominio funcional de la situación y adicionalmente, puede implicar, como en la mayoría de los casos, una afectación directa a los recursos económicos que se desvían de su fin público para trasladarse a la esfera de dominio de funcionarios y empresarios, causando perjuicio económico al Estado.

\section{EL NUEVO MARCO DE RESPONSABILIDAD PENAL DE LAS PERSONAS JURÍDICAS}

Como consecuencia de lo expuesto, el derecho está en la necesidad de crear las herramientas jurídicas necesarias para sancionar, pero principalmente, prevenir la corrupción. Las relaciones contractuales entre los Estados y las empresas generan escenarios diversos $y$, junto con ellos, se ha develado una nueva forma de criminalidad que ha encontrado importantes espacios para la configuración de una serie de delitos económicos vinculados a la infracción del deber del funcionario público con dominio funcional y con la participación de personas jurídicas. El cohecho en sus diversas modalidades, la colusión, el peculado, son algunas figuras penales que se configuran en el marco de la actividad empresarial y de la actuación de funcionarios y/o servidores públicos.

Nace así, en el derecho penal moderno, la necesidad de crear un marco de responsabilidad penal para estas figuras que involucre a las personas jurídicas, debido a que la sanción a las personas físicas, responsables de desarrollar las conductas típicas, no resultaría suficiente para ejercer un adecuado control de las actividades corruptas que se desarrollan bajo este esquema.

En esta moderna tendencia de responsabilidad penal dirigida hacia la empresa y personas jurí- dicas en sus diversas modalidades de constitución legal, éstas son consideradas como sujetos de deberes de cumplimiento $y$, ante la infracción de este deber, son susceptibles de recibir, de manera directa, sanciones específicas producto de los delitos que, en su nombre, interés o representación, hayan cometido sus representantes, funcionarios, gestores y demás actores empresariales, independientemente de si éstos últimos son penalmente sancionados o absueltos; en este nuevo marco de responsabilidad penal de la persona jurídica, la organización societaria es sancionada de manera autónoma por la infracción de su deber de cumplimiento del marco normativo que estaba comprometida a proteger, respetar y velar por su adecuada aplicación.

\section{El delito corporativo y el Compliance.}

En la doctrina moderna, existen debates y distintas posiciones adoptadas en torno a los delitos corporativos. El Compliance penal o "Criminal Compliance", se ha convertido en un modelo acogido por la gran mayoría de las legislaciones occidentales del Civil Law. Sin embargo, la incorporación de este modelo genera una consecuencia natural de discusión que radica en la importancia de trasladar la teoría general del delito desde la persona física - persona naturalhacia la persona jurídica.

¿De qué manera se puede entonces determinar la responsabilidad penal de una persona jurídica de forma independiente de la responsabilidad de la persona física que desarrolla la acción? Surge una interrogante obligada orientada a responder cómo opera el Compliance y cuál es su verdadero rol en un contexto penal.

Si como hasta ahora se ha analizado, la tendencia adoptada a partir del Compliance establece un marco de responsabilidad independiente o autónoma para la persona jurídica, cabe preguntarse cómo opera esta responsabilidad en la práctica. Es así que, el Compliance se puede convertir en una forma de conducta con reproche penal cuya infracción radica precisamente en incumplir la norma jurídica. Esta definición se puede comprender dentro del concepto doctrinario que se aplica a los delitos de peligro abstracto, en los 
cuales la infracción penal se configura por la sola generación de un riesgo potencial para la seguridad de la sociedad, sin que sea necesario lesionar algún bien jurídico en concreto. De esta forma, se fija el camino jurídico para el nuevo ámbito de la responsabilidad empresarial autónoma.

En esta línea de razonamiento, la persona jurídica incurre en una situación de incumplimiento si es que no adopta un modelo de Compliance al interior de su organización, o si contando con uno, no ejerce su responsabilidad de hacerlo efectivo o de aplicar sus mecanismos de denuncia por las conductas que lo vulneren. Es precisamente este incumplimiento el que se sanciona, independientemente del delito cometido por la persona natural involucrada en un hecho penal.

Sobre este aspecto del denominado "delito corporativo", el experto español Iñigo Gómez ${ }^{3}$ opina: "Nace así lo que la doctrina más avanzada en esta materia ha bautizado, con mucho acierto a nuestro entender, como el Delito Corporativo, un tipo penal que operará de forma independiente del delito cometido por la persona física".

Así, un importante sector de la doctrina considera al nuevo delito corporativo como un delito de riesgo, de peligro abstracto, en la medida que se sanciona el incumplimiento normativo de la persona jurídica aun cuando se determine que la persona natural no cometió delito, es decir no lesionó bien jurídico alguno. Entonces, en este escenario, el derecho penal actúa "exante" previniendo las lesiones a bienes jurídicos concretos, reprochando la lesión a la conducta debida de cumplir con la norma, en este caso específico, con el Compliance.

Sería materia de otro análisis, cómo esta figura del delito corporativo se adapta a los requisitos de la teoría del delito para determinar la culpabilidad, la antijuridicidad, la aplicación del principio de lesividad y establecer dogmáticamente, de qué forma la persona jurídica que no cumple con el Criminal Compliance, eleva el riesgo permitido a su actividad empresarial y lo convierte en potencialmente lesivo para la sociedad al transgredir su deber de cumplimiento normativo.

La preocupación dogmática sobre este punto de discusión, radica a su vez en que se podría estar frente a situaciones de responsabilidad objetiva, donde el solo incumplimiento sería la causa de una sanción penal. Sin embargo, los avances en este nuevo modelo de responsabilidad de la persona jurídica están adoptando, como en el caso español, criterios jurisprudenciales para regular los requisitos para procesar a una persona jurídica, marcándose pautas para su absolución o condena.

\section{La Responsabilidad Administrativa de las Personas Jurídicas y el Criminal Compliance.}

Se consolida entonces el Criminal Compliance como una herramienta para enfrentar la creciente corrupción controlando el denominado riesgo empresarial, evitando que los riesgos propios de una actividad económica se conviertan en una potencial amenaza para la confianza que la sociedad deposita en las personas jurídicas y especialmente para el correcto ejercicio de la función pública y el uso adecuado de los recursos del Estado.

El Compliance, del inglés "To comply with" —“"cumplir con"-, es un término adoptado del derecho anglosajón que existe como figura jurídica desde hace muchas décadas, sobre todo en los Estados Unidos de América, de donde provienen las principales experiencias en esta regulación ${ }^{4}$.

3. GÓMEZ, IÑIGO. El Delito Corporativo. España: Gobercom España. Organización de expertos especializados en Compliance Penal, 2017.

4. En 1997, en los Estados Unidos se aprueba la "Foreign Corrupt Practices Act" para regular las prácticas corruptas y prohibir los sobornos internacionales entre empresas americanas y funcionarios dentro y fuera de los Estados Unidos. Asimismo, la Sarbanes Oxley Act, 2002, - Ley Sarox, exige a las empresas cumplir con exactitud los registros y asientos contables; su incumplimiento se sanciona con penas que van desde multas hasta la liquidación judicial de la sociedad infractora. 
En los años más recientes, las tendencias globales contra las prácticas corruptas exigen que los Estados adopten medidas unificadas y dirigidas a brindar un apoyo efectivo contra este flagelo.

Instrumentos internacionales como la Convención de las Naciones Unidas contra la Corrupción y la Convención Interamericana contra la Corrupción contienen lineamientos de política globales para la lucha contra la corrupción a través de las empresas y al mismo tiempo, promueven la ética y la integridad de la conducta en el desempeño de la función pública, procurando una actividad empresarial transparente y respetuosa del marco jurídico vigente en cada país, que no deberá ser transgredido ni afectado.

De esta forma, el Compliance se asienta con fuerza en las legislaciones occidentales, como una herramienta que regula una conducta positiva de la persona jurídica, en base al desarrollo de modelos internos de control normativo, que deben ser elaborados sobre el análisis de diversos factores vinculados al contexto en el que la empresa desarrolla su actividad societaria, los riesgos a los que puede enfrentarse en sus relaciones comerciales, las políticas internas de control, códigos de conducta, prohibiciones de transgredir las normas penales y en general, el cumplimiento del marco normativo asociado al giro del negocio. Pero, sobre todo, el eje de los modelos de Compliance radica en un adecuado sistema de monitoreo y en el establecimiento de un protocolo para la detección de riesgos, acompañado de un sistema de denuncias en caso de que, pese a la adecuada aplicación del modelo, el riesgo se haga efectivo y se lesionen bienes jurídicamente protegidos.

He aquí la importancia del Compliance y la necesidad de su comprensión. La empresa está obligada a realizar su actividad económica en estricto respeto a las leyes y al marco normativo en general. La organización asume de esta forma una conducta de legalidad y a través de sus modelos de Compliance debe promover la ética y las buenas prácticas comerciales, asegurando que sus funcionarios, representantes, gestores, servidores, respeten estrictamente el modelo.

Pero el rol de la empresa en el Compliance va más allá: La empresa se compromete a desarrollar una conducta preventiva, a monitorear activamente el cumplimiento de sus modelos y está comprometida con denunciar los casos de transgresión. De no hacerlo, asume responsabilidad independiente y será sujeto de las sanciones que le resulten aplicables como consecuencia directa de su incumplimiento normativo. Al respecto y analizando el caso peruano, el Dr. Carlos Gómez-Jara Diez dice: "El modelo de prevención de la nueva legislación peruana sienta una de sus premisas basales en el ámbito de la gestión del riesgo".

\section{EL DERECHO PENAL Y LAS PERSONAS JURÍDICAS: EL CASO PERUANO}

Es importante iniciar este punto, haciendo mención que en el Perú coexisten dos modelos de responsabilidad aplicables a las personas jurídicas dentro de un proceso penal: Por un lado, el artículo 105 del Código Penal y por otro, la Ley 30424 y su modificatoria, el Decreto Legislativo 1352, que regulan la "responsabilidad administrativa autónoma de las personas jurídicas" para los delitos específicamente contemplados en estas normas.

\section{El artículo 105 del Código Penal Peruano.}

El artículo 105 del Código Penal Peruano de 1991, regula las "consecuencias accesorias para las personas jurídicas". Como su propio nombre lo dice, se trata de medidas aplicables a las personas jurídicas, involucradas en conductas penalmente reprochables, de manera accesoria y dependiente de la condena que se aplique a las personas físicas sentenciadas por la comisión de un delito, cuando éste haya sido cometido en ejercicio de su actividad comercial o en uso de la organización y siempre que la organiza- 
ción social haya sido incorporada a la investigación fiscal y al proceso penal.

Sin embargo, la aplicación de estas consecuencias accesorias a las personas jurídicas no tiene un tratamiento claro en nuestra jurisprudencia. Sobre este aspecto, la Corte Suprema de Justicia de la República aprobó el Acuerdo Plenario No 007-2009, cuya importancia radica en el hecho que, se estableció como criterio unificador de jurisprudencia que la persona jurídica podrá sufrir las consecuencias accesorias de un delito, cuando esta sea incorporada a un proceso penal con todas las garantías procesales que protejan el debido proceso y garanticen el derecho a la defensa material y procesal, aplicándose las reglas contenidas en el artículo 90 y siguientes del Código Procesal Peruano del año 2004.

\section{La Ley 30424 y el Decreto Legislativo 1352.}

A partir del año 2016, se introduce en nuestra legislación peruana el modelo del Compliance con la aprobación de la Ley $30424^{6}$ para el caso específico del delito de Cohecho Activo Trasna- cional tipificado en el artículo 397-A del Código Penal, siendo las sanciones aplicables multas, inhabilitación para continuar operando, inhabilitación para contratar con el Estado, cancelación de licencias y disolución. Es en esta norma jurídica donde se establece la responsabilidad autónoma de la persona jurídica?.

En esta ley se incorpora por primera vez el Compliance como un modelo de prevención ${ }^{8}$, que puede configurarse como un eximente de responsabilidad si se prueba, dentro del proceso penal, que éste fue adoptado con anterioridad a la comisión del delito y se aprecia la contradicción entre la establecida responsabilidad "administrativa" de la persona jurídica y el carácter penal de la figura. Precisamente en las disposiciones finales de la citada Ley 30424, se hace expresa mención a que esta responsabilidad administrativa se establece y sanciona en el marco de un proceso penal'.

Posteriormente, se aprueba y publica el Decreto Legislativo $1352^{10}$, ampliándose la responsabilidad "administrativa" de las personas jurídicas para los delitos de cohecho trasnacional,

6. Ley 30424 del 20 de abril de 2016. Ley que regula la Responsabilidad Administrativa de las Personas Jurídicas por el delito de Cohecho Activo Transnacional. Diario Oficial El Peruano.

7. Ley 30424. "Artículo 4. Autonomía de la responsabilidad administrativa de la persona jurídica y extinción de la acción contra la persona jurídica

La responsabilidad administrativa de la persona jurídica es autónoma de la responsabilidad penal de la persona natural. Las causas que extinguen la acción penal contra la persona natural no enervan la responsabilidad administrativa de las personas jurídicas. La acción contra la persona jurídica se extingue por prescripción, cosa juzgada, amnistía o el derecho de gracia. La prescripción de la acción contra la persona jurídica se rige por lo dispuesto, en lo que corresponda, en los artículos 80, 82, 83 y 84 del Código Penal".

8. Ley 30424. Artículo 17. Eximente por implementación de modelo de prevención

17.1. La persona jurídica está exenta de responsabilidad administrativa por la comisión del delito de cohecho activo transnacional, si adopta e implementa en su organización, con anterioridad a la comisión del delito, un modelo de prevención adecuado a su naturaleza, riesgos, necesidades y características, consistente en medidas de vigilancia y control idóneas para prevenir el delito de cohecho activo transnacional o para reducir significativamente el riesgo de su comisión."

9. Ley 30424. Tercera Disposición Complementaria Final. Vía procesal La investigación, procesamiento y sanción de las personas jurídicas, de conformidad con lo establecido en la presente Ley, se tramitan en el marco del proceso penal, al amparo de las normas y disposiciones del Código Procesal Penal, aprobado por el Decreto Legislativo 957.

10. Decreto Legislativo 1352. 07 de enero de 2018. Amplía la responsabilidad penal de las personas jurídicas. Publicado en el Diario Oficial El Peruano.

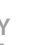

(n) 
doméstico, lavado de activos y financiación del terrorismo.

Importante destacar que la ley peruana considera una denominación amplia para el concepto de persona jurídica, abarcando todo tipo de sociedades, fundaciones, organizaciones no gubernamentales y comités no inscritos, además empresas públicas y entidades fiduciarias.

Las reglas para la aplicación de la figura de responsabilidad administrativa son diversas. La atribución de responsabilidad administrativa a la empresa, parte del hecho que el delito haya sido cometido en su nombre, por cuenta de la empresa o en su beneficio; se incorpora entonces un elemento subjetivo del "interés" que en la práctica puede ser de difícil probanza para eximir de responsabilidad a la empresa. Contrario sensu, el objeto de la prueba se centraría en estos casos en determinar si la persona natural actuó en nombre propio, por su interés particular o incumpliendo los parámetros del modelo de cumplimiento adoptado al interior de la persona jurídica.

A partir del año 2019, entró en vigencia el reglamento de la Ley $30424^{11}$ que regula fundamentalmente los modelos, estándares, componentes, requisitos mínimos y aplicabilidad de los modelos de prevención -Compliance-, ratificando así la importancia de esta figura para el nuevo modelo penal donde la empresa deja de ser un tercero civil, un espectador y se convierte en un actor procesal con deberes, pero también con derechos procesales y garantías para la defensa material y el debido proceso. Esta posición ha sido también abordada en el derecho español y al respecto Juan Luis Gómez Colomer" dice: "La pregunta inicial que surge inmediatamente, partiendo de esta configuración constitucional del proceso penal, al ser la persona jurídica parte pasiva en el mismo, es la de si gozará exactamente igual que un imputado o acusado persona física de los mismos derechos fundamentales que la Constitución reconoce a éste".

\section{3. ¿Responsabilidad Penal o Administrativa?}

En la mayoría de las legislaciones bajo el modelo del Civil Law, el Compliance se adopta como una responsabilidad penal corporativa. Destaca el caso peruano en la medida que, la adopción de la figura del Compliance ha sido incorporada, como ya se dijo, a nuestro sistema penal bajo la denominación de Responsabilidad Administrativa de las Personas Jurídicas.

Esta denominación puede prestarse a cierto grado de confusión, más aún si la responsabilidad administrativa de una persona jurídica puede producirse en el ámbito del derecho administrativo, específicamente en el derecho administrativo sancionador que puede establecer la responsabilidad administrativa de una persona jurídica cuando, en el marco de una actuación empresarial en la esfera del sector público, ésta genere lesiones a normas administrativas, recibiendo sanciones diversas que están amparadas por principios muy similares a los que inspiran al derecho penal, como son el principio de legalidad, la taxatividad, proporcionalidad y la presunción de buena fe, que se asemeja, salvando las diferencias, con el principio constitucional de la presunción de inocencia que es una de las máximas garantías y controles al lus Punendi del Estado.

¿Cómo se comprende entonces esta nueva legislación de "responsabilidad administrativa de las personas jurídicas" dentro del ámbito penal? De la lectura de la normativa se desprende que, si bien el nombre de la figura hace alusión a una responsabilidad administrativa, la regulación está orientada a definir en el fondo una responsabilidad penal pero con consecuencias administrativas para la empresa; vale decir,

11. Decreto Supremo No 002-2019-JUS. Publicado en el Diario Oficial El Peruano el 09 de enero de 2019.

12. GÓMEZ, Juan Luis. El Derecho Penal Económico en la Era Compliance. Valencia: 2013. 
existe una cierta "dualidad" o falta de posición doctrinaria frente a este nuevo modelo en el ordenamiento peruano, más aún si, la aplicación del derecho administrativo sancionador no limita que, si en el desarrollo del procedimiento administrativo sancionador se advierten conductas que puedan configurar ilícitos penales, se cursen partes al Ministerio Público para las investigaciones correspondientes contra quienes resulten responsables.

Se evidencia entonces que el espíritu del Compliance es específico, buscando prevenir la infracción, mediante el compromiso de la empresa de actuar en un marco de respeto normativo orientado a minimizar riesgos y establecer estrictos mecanismos de control interno en la organización para actuar conforme a la norma, tomando acción directa cuando, dentro del uso del modelo de Compliance, las personas naturales cometan conductas presuntamente ilícitas. De esta forma, a través de la denuncia, el Estado conoce de los hechos y se activa el aparato jurisdiccional.

\section{La Doble Dimensión del Compliance.}

El Compliance se ha incorporado en la legislación peruana y occidental con una doble dimensión: Por un lado, es una herramienta procesal que permitirá a la empresa actuar en un proceso penal cuando se vea comprometida en un delito cometido por alguna persona física de su organización, bajo las reglas y parámetros anteriormente desarrollados; y por otro lado, existe la dimensión empresarial del Compliance, que pasa de ser un "Criminal Compliance" para convertirse en un "Corporate Compliance".

En el modelo del Corporate Compliance, el criterio de cumplimiento supera el ámbito de la norma penal y se extiende hacia una política de sujeción al derecho en general, abordando el respeto al marco normativo específico que regula la actividad empresarial, pasando por el cumplimiento de normas a favor del medio ambiente, de la protección al consumidor, de la libre competencia y otras. El Compliance corporativo se interioriza en las empresas, pequeñas, medianas y hasta en las grandes corporaciones como un sistema de cumplimiento normativo integral, que, con sus propias reglas y protocolos de seguimiento, monitoreo y evaluación, se convierte en una importante herramienta que conecta a la organización con el nuevo modelo de ética corporativa. Precisamente sobre este punto, el profesor Percy García Cavero ${ }^{13}$ hace mención a la creación del concepto de "responsabilidad social corporativa" destinado a "irradiar valores éticos a la actuación empresarial, a nivel de su gestión y administración".

En este nuevo modelo de gestión corporativa, la persona jurídica asume, frente a la sociedad, el reto de proyectarse no solamente hacia lo que sus consumidores esperan, sino hacia una práctica empresarial transparente y ajustada a derecho. Es así que la nueva visión empresarial apuesta por respetar las normas que promueven la protección al medio ambiente, la protección a los derechos de los consumidores, promover las buenas prácticas y en general aplicar un cambio orientado hacia una mejor imagen corporativa. Sobre esto, el profesor Percy García Cavero ${ }^{14}$ sostiene que se trata de: "una función de confirmación del derecho que se materializa en el establecimiento de diversos mecanismos confiables y seguros para la detección interna de las irregularidades cometidas".

\section{CONCLUSIONES}

El análisis efectuado nos permite concluir que:

a) El Compliance es un modelo de cumplimiento normativo adoptado del derecho

13. GARCÍA, Percy. Criminal Compliance en Especial Compliance Anticorrupción y Lavado de Activos. Primera Edición. Lima: Instituto Pacífico, 2017.

14. GaRCíA CAVERO, Percy. Op. Cit. 
anglosajón que se ha incorporado a la mayoría de las legislaciones del Civil Law.

b) El Criminal Compliance establece un sistema de responsabilidad penal para las personas jurídicas que se aplica de manera autónoma a la responsabilidad penal de la persona natural involucrada.

c) Su factor de atribución de responsabilidad radica en el incumplimiento normativo o en el inadecuado cumplimiento del modelo de prevención.

d) La implementación y correcta aplicación de los modelos de prevención permiten a la empresa deslindar su responsabilidad en el delito con las reglas establecidas en la regulación normativa aplicable. e) En el Perú, la responsabilidad administrativa de la persona jurídica encierra un modelo de responsabilidad penal que no ha sido denominado como tal pero que se sujeta a los procedimientos y garantías que regulan el proceso penal.

f) Un efectivo modelo de Compliance debe contener los elementos mínimos que lo hagan eficaz para su finalidad que es prevenir delitos y minimizar riesgos.

g) El Compliance se extiende a un cumplimiento normativo de todos los ámbitos del derecho, asumiéndose el Compliance Corporativo como una necesidad empresarial de adaptarse a las reglas éticas y de cumplimiento de la norma jurídica. 